\title{
Preventing nausea and vomiting in women undergoing regional anesthesia for cesarean section: challenges and solutions
}

\author{
Yvonne Jelting' \\ Christian Klein' \\ Thomas Harlander' \\ Leopold Eberhart ${ }^{2}$ \\ Norbert Roewer' \\ Peter Kranke' \\ 'Department of Anesthesia and \\ Critical Care, University Hospitals of \\ Wuerzburg, Wuerzburg, ${ }^{2}$ Department \\ of Anesthesiology and Critical Care \\ Medicine, Philipps-University Marburg, \\ Marburg, Germany
}

This article was published in the following Dove Press journal:

Local and Regional Anesthesia

9 August 2017

Number of times this article has been viewed

Background: Intraoperative nausea and vomiting (IONV) or postoperative nausea and vomiting (PONV) affecting women undergoing regional anesthesia for cesarean section is an important clinical problem since these techniques are used widely. There are burdens of literature about IONV/PONV and several in parturient and cesarean. However, it needs more attention. The underlying mechanisms of IONV and PONV in the obstetrical setting mainly include hypotension due to sympathicolysis during neuraxial anesthesia, bradycardia owing to an increased vagal tone, the visceral stimulation via the surgical procedure and intravenously administered opioids. Methods: Given the high and even increasing rate of cesarean sections and the sparse information on the etiology, incidence and severity of nausea and vomiting and the impact of prophylactic measures on the incidence of PONV/IONV, this article aims to review the available information and provide pragmatic suggestions on how to prevent nausea and vomiting in this patient cohort. Current literature and guidelines were identified by electronic database searching (MEDLINE via PubMed and Cochrane database of systematic reviews) up to present, searching through reference lists of included literature and personal contact with experts.

Discussion and conclusion: Taking into account the current guidelines and literature as well as everyday clinical experience, the first step for decreasing the incidence of IONV and PONV is a comprehensive management of circulatory parameters. This management includes liberal perioperative fluid administration and the application of vasopressors as the circumstances require. By using low-dose local anesthetics, an additional application of intrathecal or spinal opioids or hyperbaric solutions for a sufficient controllability of neuraxial distribution, maternal hypotension might be reduced. Performing a combined spinal-epidural anesthesia or epidural anesthesia may be considered as an alternative to spinal anesthesia. Antiemetic drugs may be administered restrainedly due to off-label use in pregnant women for IONV or PONV prophylaxis and may be reserved for treatment.

Keywords: obstetrics, antiemetics, hypotension, PONV, neuraxial anesthesia

\section{Background}

Postoperative nausea and vomiting (PONV) is an important clinical problem that still affects patients undergoing surgery with general anesthesia. With no prior prophylaxis, approximately $30 \%$ of all patients suffer from nausea and vomiting in the postanesthetic period, whereby the highest incidence can be found in the first 6 hours after surgery. ${ }^{1}$

Compared to the plethora of literature about PONV, little attention has been paid to nausea and vomiting occurring during or after regional anesthesia. These techniques gain increasing attention. Nowadays, about $7 \%$ of all surgical procedures worldwide

Correspondence: Peter Kranke Department of Anesthesia and Critical Care, University Hospitals of Wuerzburg, Oberduerrbacher Street 6, 97080

Wuerzburg, Germany

Tel +49 93I 20l 0 (operator)

Fax +49 931 20130053

Email Kranke_p@ukw.de 
are cesarean sections $(\mathrm{CSs})^{2}$ and the majority of them are performed with neuraxial blockades, ie, epidural anesthesia (EDA), spinal anesthesia (SPA) or a combined spinal-epidural anesthesia (CSE).

Especially in these patients, nausea and vomiting are also present during the surgical procedure causing discomfort for the parturient (and her escort), impair surgical conditions for the gynecologist and can lead to medical side effects such as aspiration of gastric content, enhanced intra- and postoperative pain and even bleeding or surgical trauma. ${ }^{3}$

\section{Risks and mechanisms of PONV/ intraoperative nausea and vomiting (IONV)}

Current literature indicates a high incidence of IONV during CS under SPA up to $80 \%{ }^{4,5}$ Pregnant women are already likely to suffer from nausea and vomiting because of the pregnancy itself. This is applicable not only to the first 3 months of pregnancy but also to the third and last trimester due to the reduced tone of the esophagogastric junction and an increased intraabdominal pressure. ${ }^{6}$ Moreover, pregnant women can be assigned to a high-risk group regarding the likelihood of the occurrence of nausea and vomiting of any origin (motion sickness, chemotherapy-associated nausea and vomiting and PONV). Consulting Apfel's predictive PONV score that consists of four ascertained risk factors (female, nonsmoker, opioid use, previous PONV events or motion sickness), ${ }^{7}$ parturients often meet at least two of these criteria with their gender and the nonsmoker status. However, it remains unclear whether the same risk factors are associated with PONV and with IONV under SPA. Females undergoing CS might be affected by different mechanisms that trigger nausea and vomiting than patients who undergo general anesthesia. ${ }^{8}$

As mentioned earlier, in most cases, a cesarean delivery is performed with neuraxial analgesia techniques ${ }^{9,10}$ such as SPA or EDA. In addition, CSE analgesia is frequently used. Established medications used for an SPA or EDA (local anesthetics and opioids) have a regional effect; they do not pass the placenta to a large extent and presumably do not cause major unintended (adverse) effects to the fetus. But there are also disadvantages regarding neuraxial techniques: The injected local anesthetic does not only specifically block the pain fibers but also leads to a vasodilatation by affecting sympathetic efferences. Due to the induced temporary sympathicolysis, blood pressure fluctuation in terms of significant hypotension can occur. On top of that, the increased vagal tone entails bradycardia which is often accompanied with nausea and vomiting. ${ }^{11,12}$
Additively, patients scheduled for an elective cesarean delivery have to fast for many hours in case of the necessity for a rapid sequence induction where an emergency intubation has to be performed. Besides the expected blood loss of several hundreds of milliliters within a short time, there can also occur a major bleeding. Depending on the parturient's cardiac output and other circulatory variables, compensating huge blood loss can take several minutes. Meanwhile, the blood pressure may further decrease. These events cause a reduced perfusion of the brain. This ischemia may activate the vomiting center in the medulla oblongata. ${ }^{13}$ As a result, patients can be affected by nausea and - in worst case - vomiting. In addition, the unavoidable manipulation of the uterus and peritoneum as well as the exteriorization of the uterus during surgery can cause nausea and vomiting by activating afferent vagal afferences. ${ }^{14}$ During pregnancy, various hormonal changes happen; therefore, the sphincter tone of the esophagus decreases. In addition, uterotonic medications administered after delivery of the baby (eg, oxytocin and ergot alkaloids) may induce nausea and vomiting. ${ }^{15-17}$ For enhancing the analgesic quality, an opioid (eg, morphine or sufentanil) is frequently added. But not only for intrathecal or EDA application opioids are used. In some cases, it is also necessary to supplement regional anesthesia with a systemic injection of opioids to achieve sufficient analgesia and obtain a satisfactory pain relief. Systemic opioids can cause nausea and vomiting and therefore they represent another factor influencing the likelihood of nausea and vomiting as already shown by many studies in other patient cohorts. ${ }^{18,19}$

For all parturients and their families, a natural birth as well as a cesarean delivery represents a sentinel event in the lifetime. This excitement activates the adrenergic system. As a compensation mechanism, the parasympathetic system might be upregulated. An overreaction (in terms of a vagal hyperactivity) might also be the reason for nausea and vomiting. ${ }^{4}$ Furthermore, patients may be requested to have a fasting period prior to elective surgery, thus boosting a strange abdominal feeling that might be interpreted as feeling nauseous.

\section{Methods}

Given the high and even increasing rate of CSs and the sparse information on the etiology, incidence and severity of nausea and vomiting and the impact of prophylactic measures on the incidence of PONV/IONV, this article aims to review the available information and provide pragmatic advice on how to tackle nausea and vomiting in this patient cohort. The main focus was on the use of pharmacological interventions 
in terms of antiemetic prevention. Other measures will be discussed briefly, eg, vasopressor treatment, volume pre- and co-loading, if they are feasible in this setting and represent clinical meaningful interventions.

Current literature and guidelines were identified by electronic database searching (MEDLINE via PubMed and Cochrane database of systematic reviews) up to current, searching through reference lists of included literature and personal contact with experts.

This narrative review focuses on new challenges and solutions regarding the prevention of nausea and vomiting by reviewing the recent literature and taking current guidelines on the management of anesthesia during CS into account.

\section{Discussion: current guidelines and literature}

In 2004, the British National Institute for Health and Care Excellence published a guideline (NICE guideline) regarding anesthesia during CS for the first time and the topic was again taken up in the second, updated version which was released in $2011 .^{20}$ Some of the recommendations directly or indirectly target the prevention of nausea and vomiting. The latter are cited, briefly presented and critically evaluated by putting them into current literature context.

Women who are having a CS should be offered regional anaesthesia because it is safer and results in less maternal and neonatal morbidity than general anaesthesia. This includes women who have a diagnosis of placenta praevia. ${ }^{20}$

First, regional anesthesia should be offered to the patient as the preferred anesthesia procedure for CS. The several advantages of neuraxial procedures during CS have long been known to be most suitable for mother and newborn. Regarding PONV prevention, the non-opioid analgesics should be used to reduce the doses of opioids. In terms of PONV prevention, however, the choice of a regional anesthesia technique does only make sense if the event rate for hypotension - and consequently symptomatic hypotension is low. If hypotension occurs frequently due to inadequate preventive measures and/or is not readily treated, a regional technique by no means offers an advantage in terms of nausea prevention.

\section{Hypotension}

Women who are having a CS under regional anaesthesia should be offered intravenous ephedrine or phenylephrine, and volume pre-loading with crystalloid or colloid to reduce the risk of hypotension occurring during $\mathrm{CS}^{20}$
Intravenous ephedrine or phenylephrine should be used in the management of hypotension during CS. The operating table for CS should have a lateral tilt of $15^{\circ}$, because this reduces maternal hypotension. ${ }^{20}$

During a CS using regional anesthesia procedures, ephedrine, phenylephrine or Akrinor ${ }^{\circledR}$ (cafedrine/theodrenaline) as well as preloading with crystalloids or colloids should be used to minimize the risk of hypotension. ${ }^{11,12}$

The preemptive or early use of antihypotensive agents is an important way to avoid one of the main causes for nausea and emesis throughout CS. But simple relying on preventive administration should be avoided because of the risk of excessive blood pressure reactions and thus a possible insufficient placental supply. Ephedrine or phenylephrine is recommended as an antihypotensive drug. Meanwhile, phenylephrine may be viewed internationally as the first-choice agent. However, the use of phenylephrine is associated with an increased risk for resulting bradycardia, which makes the drug unsuitable if the heart rate is already lowered. Compared to phenylephrine, a higher rate of fetal acidosis was shown using ephedrine. Cafedrine/theodrenaline, which has a long history of use in Germany, has also a long history of use in the therapy of hypotension in the context with regional anesthesia for CS and has shown a positive side-effect profile. ${ }^{21}$ However, major clinical examinations and data are still missing. ${ }^{22,23}$ The most recent systematic review on this topic analyzed the use of prophylactic phenylephrine for CS under SPA to avoid hypotension and was published in 2014 by Heesen et al. ${ }^{24}$ The authors found out that phenylephrine offered to the parturients via infusion before the performance of CS reduced the occurrence of IONV by preventing hypotension significantly. The latter study emphasized the importance of preventing the hypotension in conjunction with the central neuraxial block.

The term "preloading" describes the administration of fluids before implementing a neuraxial method. Positive effects on the prevention of hypotension, especially in SPA, could only be shown slightly and temporarily. Physiologically, this is mainly due to the short intravascular availability of the solutions, especially crystalloids. The use of colloidal solutions is listed as a possible alternative. Hydroxyethyl starch (HES), especially new generation like HES 6\% 130/0.4, despite all criticism and limitations in the field of intensive care medicine, appears to be appropriate from the authors' point of view, since there is convincing evidence that a (mixed) colloid-crystalloid regime in different settings is better suited to maintain blood pressure and thus reduce the incidence of symptomatic hypotension than a crystalloid 
regime alone. . $5,25,26$ The "co-loading" method, ie, the rapid application of solutions during SPA is not universally and consistently considered the method of choice. ${ }^{27}$ There are still insufficient data to have a final decision on these aspects, and the underlying variation in practices and settings as well as studied cohorts of patients makes it difficult to gain a holistic and satisfying picture with regard to volume loading and the timing of this intervention.

Nevertheless, adequate infusion management seems to be important in terms of reducing significant hypotension during CS under regional anesthesia. Prehydration and liberal administration of fluids in the initial phase of neuraxial anesthesia (co-loading) decrease the occurrence of intraoperative hypotension, and therefore one of the main reasons for nausea and vomiting. Systematic reviews on this topic comparing colloids and crystalloids in the prevention of hypotension concluded that colloid infusion provided significantly better prophylaxis. ${ }^{25,26}$ Mercier et $\mathrm{al}^{5}$ conducted a randomized controlled trial (RCT) testing HES versus Ringer's lactate (RL) for preloading combined with phenylephrine. As a result, HES followed by RL infusion was most effective in reducing hypotension and proved safety. When administering colloids, preloading seems to be more effective than co-loading; for crystalloids, it may be vice versa due to a rapid redistribution. ${ }^{28}$ Overall, there is sufficient evidence to justify the use of colloid solutions in the setting of the prevention of spinal hypotension in conjunction with CS.

Optimal positioning for the avoidance of aortocaval compression syndrome, using either a lateral tilt of the operating table or alternatively a $15^{\circ}$ wedge under the women's right hip, is recommended. However, in clinical practice, this goal is rarely achieved. ${ }^{29}$ For a lateral tilt equal to $15^{\circ}$ to prevent hypotensive episodes, no definitive answer can be given based on the current literature. ${ }^{30}$ Even such a maneuver requires objective measurement, ${ }^{29}$ but finally, if not considered effective,${ }^{31}$ cannot be regarded as a measure of choice.

No adequate evidence could be found for other techniques, such as the use of elastic stockings.

\section{Prophylaxis of aspiration}

To reduce the risk of aspiration pneumonitis women should be offered antacids and drugs (such as $\mathrm{H} 2$ receptor antagonists or proton pump inhibitors) to reduce gastric volumes and acidity before $\mathrm{CS}^{20}$

The prevention of aspiration and possibly following aspiration pneumonitis is based on two considerations: on the one hand, reducing the gastric filling volume to the greatest possible extent, and on the other hand, neutralizing gastric acid largely. The volume can be significantly reduced by abstinence of food and fluids. The use of prokinetic drugs, such as metoclopramide, for enhanced volume reduction - as suggested by the European Society of Anaesthesiology (ESA) fasting guideline - may further decrease the incidence of nausea and vomiting. ${ }^{32}$

The $\mathrm{pH}$ of the gastric content can be positively influenced by several drug groups. Antacids such as sodium citrate increase the gastric $\mathrm{pH}$, the administered volume seems to be rather irrelevant. Histamine-mediated acid secretion is successfully inhibited by $\mathrm{H} 2$ blockers such as cimetidine or ranitidine. The importance of timely application before actual CS should be noted. Cimetidine is considered obsolete by now, as it inhibits more cytochrome P450-dependent metabolic processes than ranitidine and therefore causes a greater number of side effects and interactions.

In studies, a higher mean $\mathrm{pH}$ could be achieved for ranitidine instead of proton pump inhibitors. ${ }^{33}$

\section{Direct PONV prophylaxis}

Women having a CS should be offered antiemetics (either pharmacological or acupressure) to reduce nausea and vomiting during $\mathrm{CS}^{20}$

One of the challenges in preventing nausea and vomiting in women undergoing anesthesia for CS is to find the best prophylaxis and treatment for mother and the fetus or newborn with respect to efficacy and safety aspects. With respect to antiemetic drugs used for the prevention of PONV after general anesthesia, many substance classes have proven efficacy in their routine clinical use. An official license for many drugs that can be used for pregnant women is still missing due to the lack of evidence. Frequently used drugs are antihistamines such as dimenhydrinate, serotonin antagonists (eg, ondansetron), dopamine antagonists (metoclopramide) and corticosteroids (dexamethasone). ${ }^{34,35}$ Drugs from different classes seem to complement each other concerning their antiemetic effects. ${ }^{36}$

For the antiemetics granisetron, ondansetron, droperidol and metoclopramide as well as for propofol, RCTs that were performed and analyzed provided the basis for the NICE guideline.$^{20}$ The implementation of each substance resulted in a significant reduction in nausea and vomiting. A higher effectiveness could be shown for ondansetron than for metoclopramide. Former considerations on negative cost balance of ondansetron in comparison to metoclopramide leading to the NICE recommendations suggest for metoclopramide are no longer valid since most 5-hydroxytryptamine receptor 3 (5-HT3) receptor antagonists are available as generic preparations. ${ }^{20}$ 
Ondansetron is not recommended for use during pregnancy and lactation by the pharmaceutical manufacturers. Powerful studies are missing. ${ }^{35}$ However, an increasing body of evidence suggests that these drugs can be used safely in the perioperative setting also in CS patients: a marked increase in ondansetron use, prescribed to nearly one-quarter of insured pregnant women in 2014, occurring in conjunction with decreased use of promethazine and metoclopramide has been reported. ${ }^{37}$ Albeit, based on limited human pregnancy data, ondansetron has not been associated with a significantly increased risk of birth defects or other adverse pregnancy outcomes. ${ }^{38}$

Furthermore, it appears that 5-HT3 antagonists show a significant reduction in bradycardia by inhibiting BezoldJarisch reflex. ${ }^{21}$ In addition, drugs of this class reduce the incidence of itching caused by intrathecal administration of opioids, a frequently used technique to reduce the amount of local anesthetics needed for a sufficient sensory block. Furthermore, in recent years, the use of serotonin antagonists, and especially ondansetron, has gained some research and clinical interest as prophylactic measure to reduce the occurrence of hypotensive episodes. ${ }^{11}$

A systematic review on the use of antiemetic drugs was published by Griffiths et al. ${ }^{39} \mathrm{~A}$ total of $41 \mathrm{RCT}$ s with 5,046 participants conducted between 1986 and 2012 were included and analyzed regarding the occurrence of IONV and PONV. The authors found a significant reduction for both IONV and PONV with dopamine receptor antagonists (metoclopramide and droperidol) and sedatives (mostly propofol). Dexamethasone only showed a reduction concerning intraoperative symptoms but not in the postoperative setting. With serotonin receptor antagonists such as ondansetron, the authors detected a lower incidence of IONV and PONV. Despite the quite large number of included trials and participants, it was not possible to make a clear statement with regard to superiority of any drug class or the incidence of adverse effects. Voigt et al ${ }^{40}$ conducted an RCT in 2013 investigating the use of different drugs for the prevention of IONV and PONV. Groups that were under investigation included 1) tropisetron $2 \mathrm{mg}$ and metoclopramide $20 \mathrm{mg}$ versus 2) dimenhydrinate $31 \mathrm{mg}$ and dexamethasone $4 \mathrm{mg}$ versus 3 ) tropisetron $2 \mathrm{mg}$ alone or 4) placebo. The authors found out that all antiemetic drugs reduced IONV and PONV significantly. The greatest benefit was achieved with a combination of tropisetron and metoclopramide with no safety concerns. Since tropisetron is not available any more, it might be substituted by other 5-HT3 receptor antagonists, such as ondansetron or granisetron.
Dexamethasone as an antiemetic is not mentioned in the NICE guideline. Corticosteroids achieve their maximum antiemetic effect after approximately 90 minutes. Thus, premedication before the procedure might be reasonable while intravenous administration intraoperatively cannot be recommended if immediate treatment is warranted. ${ }^{41}$ However, it may be considered for combination prophylaxis in conjunction with another drug with a different receptor profile. ${ }^{40}$ Sane et $\mathrm{al}^{36}$ published results of a randomized, prospective, double-blinded study in 2015 . The trialists included 90 parturients undergoing elective CS with SPA and investigated the effectiveness of ondansetron $4 \mathrm{mg}$ or dexamethasone $8 \mathrm{mg}$ or a combination of both drugs. As a result, the incidences for both IONV and PONV were the lowest with a combination prophylaxis. The efficacy of dexamethasone as a monoprophylaxis was already shown by Cardoso et al. ${ }^{42}$ With regard to dexamethasone, it has to be taken into consideration that Basurto Ona et $\mathrm{a}^{43}$ performed a systematic Cochrane review in 2013 which indicated a higher incidence of post-dural puncture headache after SPA for CS when using dexamethasone.

Referring to an RCT by Stein et al, ${ }^{44}$ the NICE guidelines set antiemetics equal to acupressure, as no significant difference in the efficiency of both methods was shown in this particular study. Indeed, the effects of P6 point stimulation (pericard 6, also Nei Guan) have been investigated in many clinical trials.

Based on Cochrane reviews, ${ }^{45}$ efficiency in prophylaxis and therapy of PONV was demonstrated. It has to be mentioned that there is a very high heterogeneity in the used techniques as applied in the included studies (acupressure, mechanical versus electrical stimulation or acupuncture) as well as in the type and time of application (bilateral versus one-sided) and the duration of implementation for PONV prevention and therapy. However, clear results for the specific question of $\mathrm{P} 6$ stimulation during a $\mathrm{CS}$ are lacking. On this matter, studies show contradictory results. ${ }^{46,47}$ As a result, it is still not possible to make a clear and more precise recommendation concerning this special sector. In everyday use, the pharmacological intervention is applied in most cases. Arguments against stimulation are - besides the uncertain data situation - the inexperience with the technique and potential technical problems. Nevertheless, the potential effectiveness of P6 stimulation should not be ignored and may be considered especially relevant if an exposure toward pharmacological interventions should be avoided. Further studies are necessary. ${ }^{48}$ 


\section{Authors' statement and conclusion}

Taking into account the preliminary findings and everyday clinical experience, the following aspects need to be addressed for reducing the risk of IONV and PONV in patients undergoing CS with central neuraxial blockade. In the first place, it is important to provide adequate aspiration prophylaxis with histamine antagonists. The dopamine receptor antagonist metoclopramide may be considered in addition to antihistamines. To reduce nausea and vomiting associated with the hypotension induced by the central neuraxial block, a sufficient infusion of crystalloid or colloid solutions before and during the central neuraxial blockade has a significant preventive effect. On top of that, relevant deviations of the baseline blood pressure should be corrected liberally with antihypotensive drugs such as ephedrine, phenylephrine or cafedrine/theodrenaline. Concomitant measures may be considered, such as the use of low-dose local anesthetics ${ }^{49}$ the additional application of intrathecal or spinal opioids to reduce the amount of local anesthetics needed ${ }^{49}$ or the use of hyperbaric solutions for a sufficient controllability of neuraxial distribution. ${ }^{4,50}$ However, the overall impact of the local anesthetic (drug, baricity) remains poorly understood and may be less than previously anticipated..$^{50}$ The limitations of reducing the amount of local anesthetics are clearly represented by the need to establish an adequate block height to guarantee a painless CS. To circumvent these conflicting goals, the use of a CSE may be considered as a useful option. Finally, it should be noticed that the use of EDA analgesia per se is considered the most appropriate tool to prevent profound hypotensive episodes by using a cautious titration of the local anesthetics. EDA, even when applied as a single slow bolus, is considered superior in terms of hemodynamic stability when compared with intrathecal local anesthetic. ${ }^{51}$

These options should be considered first to avoid the typical hazard for pregnant women receiving regional anesthesia. Keeping one's eyes open to the incidence of nausea and vomiting can detect institutional difficulties and the necessity for further improvement. If these arrangements fail to prevent IONV and PONV, one should reflect potential causes (eg, restrictive fluid management) and reconsider the preventive options mentioned earlier by remaining alert to the gaps in anesthetic care. Otherwise, there are two further possibilities of choice: prophylaxis of IONV/PONV occurrence or immediate and sufficient treatment. Many drugs that are standard treatment of PONV are used rather reluctantly for parturients. In most cases, reliable evidence is still lacking whether these drugs can be used without hesitation. Therefore, almost all drugs are applied without a dedicated label by the manufacturer. However, to ensure an enhanced recovery, prophylactic measure might be reasonable, eg, ondansetron, which gained attraction in recent trials also to prevent hypotension. ${ }^{11}$ More studies investigating efficacy and safety aspects have to be conducted to assure reliable results and recommendations. Evidently, physicians have to bear in mind the risk-benefit profile when administering antiemetic drugs. Since hypotension is the most important single causal factor for the occurrence of IONV or PONV in conjunction with regional anesthesia, we would like to challenge the NICE recommendation to offer antiemetic prevention apart from dedicated cases. In summary, we would like to question as to whether offering specific antiemetic prophylaxis apart from preventing hypotension in conjunction with central neuraxial block in a rigorous manner is really justified.

\section{Acknowledgment}

This work was funded by institutional resources only.

\section{Disclosure}

PK received lecture fees from Ratiopharm $\mathrm{GmbH}$, Germany. $\mathrm{LE}$ received honorarium for lectures from Baxter $\mathrm{GmbH}$, Fresenius $\mathrm{GmbH}$, Grunenthal $\mathrm{GmbH}$, Sintetica $\mathrm{GmbH}$ and Ratiopharm $\mathrm{GmbH}$, Germany. He is a member of advisory board of Grunenthal $\mathrm{GmbH}$ and Ratiopharm GmbH, Germany. The other authors report no conflicts of interest in this work.

\section{References}

1. Apfel CC, Kranke P, Katz MH, et al. Volatile anaesthetics may be the main cause of early but not delayed postoperative vomiting: a randomized controlled trial of factorial design. Br J Anaesth. 2002;88(5):659-668.

2. Weiser TG, Haynes AB, Molina G, et al. Size and distribution of the global volume of surgery in 2012. Bull World Health Organ. 2016;94(3):201F-209F.

3. Kranke P, Eberhart LH. Possibilities and limitations in the pharmacological management of postoperative nausea and vomiting. Eur $J$ Anaesthesiol. 2011;28(11):758-765.

4. Balki M, Carvalho JC. Intraoperative nausea and vomiting during cesarean section under regional anesthesia. Int JObstet Anesth. 2005;14(3):230-241.

5. Mercier FJ, Diemunsch P, Ducloy-Bouthors AS, et al; CAESAR Working Group. 6\% hydroxyethyl starch (130/0.4) vs Ringer's lactate preloading before spinal anaesthesia for Caesarean delivery: the randomized, double-blind, multicentre CAESAR trial. Br J Anaesth. 2014;113(3):459-467.

6. Kranke P, Eberhart L. [Nausea and Vomiting in the Perioperative Phase (PONV). Risk Assessment, Prevention and Therapy in Clinical Practice]. Cologne: Deutscher Ärzte-Verlag; 2012.

7. Apfel CC, Kranke P, Eberhart LH. Comparison of surgical site and patient's history with a simplified risk score for the prediction of postoperative nausea and vomiting. Anaesthesia. 2004;59(11):1078-1082.

8. Sakata K, Yoshimura N, Tanabe K, Kito K, Nagase K, Iida H. Prediction of hypotension during spinal anesthesia for elective cesarean section by altered heart rate variability induced by postural change. Int J Obstet Anesth. 2017;29:34-38.

9. Bowring J, Fraser N, Vause S, Heazell AE. Is regional anaesthesia better than general anaesthesia for caesarean section? J Obstet Gynaecol. $2006 ; 26(5): 433-434$ 
10. Jenkins JG, Khan MM. Anaesthesia for Caesarean section: a survey in a UK region from 1992 to 2002. Anaesthesia. 2003;58(11):1114-1118.

11. Heesen M, Klimek M, Hoeks SE, Rossaint R. Prevention of spinal anesthesia-induced hypotension during cesarean delivery by 5-hydroxytryptamine-3 receptor antagonists: a systematic review and metaanalysis and meta-regression. Anesth Analg. 2016;123(4):977-988.

12. Langesaeter E, Rosseland LA, Stubhaug A. Continuous invasive blood pressure and cardiac output monitoring during cesarean delivery: a randomized, double-blind comparison of low-dose versus high-dose spinal anesthesia with intravenous phenylephrine or placebo infusion. Anesthesiology. 2008;109(5):856-863.

13. Borgeat A, Ekatodramis G, Schenker CA. Postoperative nausea and vomiting in regional anesthesia: a review. Anesthesiology. 2003;98(2):530-547.

14. Ishiyama T, Yamaguchi T, Kashimoto S, Kumazawa T. Effects of epidural fentanyl and intravenous flurbiprofen for visceral pain during cesarean section under spinal anesthesia. J Anesth. 2001;15(2):69-73.

15. Broussard CN, Richter JE. Nausea and vomiting of pregnancy. Gastroenterol Clin North Am. 1998;27(1):123-151.

16. Wahab MA, Karantzis P, Eccersley PS, Russell IF, Thompson JW, Lindow SW. A randomised, controlled study of uterine exteriorisation and repair at caesarean section. Br J Obstet Gynaecol. 1999;106(9):913-916.

17. Koch KL, Frissora CL. Nausea and vomiting during pregnancy. Gastroenterol Clin North Am. 2003;32(1):201-234,vi.

18. Apfel CC, Roewer N. Einflussfaktoren von Übelkeit und Erbrechen nach Narkosen: Fiktionen und Fakten. [Risk factors for nausea and vomiting after general anesthesia: fictions and facts]. Anaesthesist. 2000;49(7):629-642. German.

19. Apfel CC, Laara E, Koivuranta M, Greim CA, Roewer N. A simplified risk score for predicting postoperative nausea and vomiting: conclusions from cross-validations between two centers. Anesthesiology. 1999;91(3):693-700.

20. Royal College of Obstetricians and Gynaecologists [homepage on the Internet]. Caesarean Section 2011: NICE Clinical Guidelines; 2011. Available from: https://www.nice.org.uk/guidance/cg132. Accessed July 03, 2017.

21. Bein B, Christ T, Eberhart LHJ. Cafedrine/theodrenaline (20:1) is an established alternative for the management of arterial hypotension in Germany - a review based on a systematic literature search. Front Pharmacol. 2017;8:68.

22. Clemens KE, Quednau I, Heller AR, Klaschik E. Impact of cafedrine/ theodrenaline (Akrinor(R)) on therapy of maternal hypotension during spinal anesthesia for Cesarean delivery: a retrospective study. Minerva Ginecol. 2010;62(6):515-524.

23. Bürkle H. Prophylaxe und Therapie der Hypotension bei der Sectio caesarea: Refresher Course DAAF DAC; 2011. Available from: www.aionline.info/abstracts/pdf/dacAbstracts/2011/041_buerkle.pdf. Accessed February 1, 2017.

24. Heesen M, Kolhr S, Rossaint R, Straube S. Prophylactic phenylephrine for caesarean section under spinal anaesthesia: systematic review and meta-analysis. Anaesthesia. 2014;69(2):143-165.

25. Cyna AM, Andrew M, Emmett RS, Middleton P, Simmons SW. Techniques for preventing hypotension during spinal anaesthesia for caesarean section. Cochrane Database Syst Rev. 2006;(4):CD002251.

26. Ripolles Melchor J, Espinosa A, Martinez Hurtado E, et al. Colloids versus crystalloids in the prevention of hypotension induced by spinal anesthesia in elective cesarean section. A systematic review and metaanalysis. Minerva Anestesiol. 2015;81(9):1019-1030.

27. Banerjee A, Stocche RM, Angle P, Halpern SH. Preload or coload for spinal anesthesia for elective Cesarean delivery: a meta-analysis. Can J Anaesth. 2010;57(1):24-31.

28. Mercier FJ. Fluid loading for cesarean delivery under spinal anesthesia: have we studied all the options? Anesth Analg. 2011;113(4):677-680.

29. Aust H, Koehler S, Kuehnert M, Wiesmann T. Guideline-recommended 15 degrees left lateral table tilt during cesarean section in regional anesthesiapractical aspects: an observational study. J Clin Anesth. 2016;32:47-53.

30. Cluver C, Novikova N, Hofmeyr GJ, Hall DR. Maternal position during caesarean section for preventing maternal and neonatal complications. Cochrane Database Syst Rev. 2010;(6):CD007623.
31. Higuchi H, Takagi S, Zhang K, Furui I, Ozaki M. Effect of lateral tilt angle on the volume of the abdominal aorta and inferior vena cava in pregnant and nonpregnant women determined by magnetic resonance imaging. Anesthesiology. 2015;122(2):286-293.

32. Smith I, Kranke P, Murat I, et al; European Society of Anaesthesiology. Perioperative fasting in adults and children: guidelines from the European Society of Anaesthesiology. Eur J Anaesthesiol. 2011;28(8):556-569.

33. Clark K, Lam LT, Gibson S, Currow D. The effect of ranitidine versus proton pump inhibitors on gastric secretions: a meta-analysis of randomised control trials. Anaesthesia. 2009;64(6):652-657.

34. Gill SK, Einarson A. The safety of drugs for the treatment of nausea and vomiting of pregnancy. Expert Opin Drug Saf. 2007;6(6):685-694.

35. Nassen CA, Schaefer C, Wirbelauer J, Honig A, Kranke P. Anästhesie und Analgesie in der Stillperiode. Kriterien der Medikamentenauswahl. [Anesthesia and analgesia in the lactation period. Criteria for drug selection]. Der Anaesthesist. 2014;63(5):415-421. German.

36. Sane S, Hasanlui MV, Abbasivash R, Mahoori A, Hashemi ST, Rafiei F. Comparing the effect of intravenous dexamethasone, intravenous ondansetron, and their combination on nausea and vomiting in cesarean section with spinal anesthesia. Adv Biomed Res. 2015;4:230.

37. Taylor LG, Bird ST, Sahin L, et al. Antiemetic use among pregnant women in the United States: the escalating use of ondansetron. Pharmacoepidemiol Drug Saf. 2017;26(5):592-596.

38. Kennedy D. Ondansetron and pregnancy: understanding the data. Obstet Med. 2016;9(1):28-33.

39. Griffiths JD, Gyte GM, Paranjothy S, Brown HC, Broughton HK, Thomas J. Interventions for preventing nausea and vomiting in women undergoing regional anaesthesia for caesarean section. Cochrane Database Syst Rev. 2012;(9):CD007579.

40. Voigt M, Frohlich CW, Huttel C, et al. Prophylaxis of intra- and postoperative nausea and vomiting in patients during cesarean section in spinal anesthesia. Med Sci Monit. 2013;19:993-1000.

41. Rusch D, Arndt C, Martin H, Kranke P. The addition of dexamethasone to dolasetron or haloperidol for treatment of established postoperative nausea and vomiting. Anaesthesia. 2007;62(8):810-817.

42. Cardoso MM, Leite AO, Santos EA, Gozzani JL, Mathias LA. Effect of dexamethasone on prevention of postoperative nausea, vomiting and pain after caesarean section: a randomised, placebo-controlled, doubleblind trial. Eur J Anaesthesiol. 2013;30(3):102-105.

43. Basurto Ona X, Uriona Tuma SM, Martinez Garcia L, Sola I, Bonfill Cosp X. Drug therapy for preventing post-dural puncture headache. Cochrane Database Syst Rev. 2013;(2):CD001792.

44. Stein DJ, Birnbach DJ, Danzer BI, Kuroda MM, Grunebaum A, Thys DM. Acupressure versus intravenous metoclopramide to prevent nausea and vomiting during spinal anesthesia for cesarean section. Anesth Analg. 1997;84(2):342-345.

45. Lee A, Chan SK, Fan LT. Stimulation of the wrist acupuncture point PC6 for preventing postoperative nausea and vomiting. Cochrane Database Syst Rev. 2015;(11):CD003281.

46. Ho CM, Tsai HJ, Chan KH, Tsai SK. P6 acupressure does not prevent emesis during spinal anesthesia for cesarean delivery. Anesth Analg. 2006;102(3):900-903.

47. Noroozinia H, Mahoori A, Hasani E, Gerami-Fahim M, Sepehrvand N. The effect of acupressure on nausea and vomiting after cesarean section under spinal anesthesia. Acta Med Iran. 2013;51(3):163-167.

48. Streitberger K, Kranke P. Evidence for the efficacy of acupressure for preventing post-operative nausea and vomiting: an ongoing debate. Eur J Anaesthesiol. 2011;28(6):396-398.

49. Roofthooft E, Van de Velde M. Low-dose spinal anaesthesia for Caesarean section to prevent spinal-induced hypotension. Curr Opin Anaesthesiol. 2008;21(3):259-262.

50. Sng BL, Siddiqui FJ, Leong WL, et al. Hyperbaric versus isobaric bupivacaine for spinal anaesthesia for caesarean section. Cochrane Database Syst Rev. 2016;9:CD005143.

51. Robson SC, Boys RJ, Rodeck C, Morgan B. Maternal and fetal haemodynamic effects of spinal and extradural anaesthesia for elective caesarean section. Br J Anaesth. 1992;68(1):54-59. 


\section{Publish your work in this journal}

Local and Regional Anesthesia is an international, peer-reviewed, open access journal publishing on the development, pharmacology, delivery and targeting and clinical use of local and regional anesthetics and analgesics. The journal is included in PubMed, and welcomes submitted papers covering original research, basic science, clinical studies, reviews and evaluations, guidelines, expert opinion and commentary, case reports and extended reports. The manuscript management system is completely online and includes a very quick and fair peer-review system, which is all easy to use. Visit http://www.dovepress.com/ testimonials.php to read real quotes from published authors.

Submit your manuscript here: https://www.dovepress.com/local-and-regional-anesthesia-journal 